\title{
Co-designing a digital platform with boundary objects: bringing together heterogeneous users in healthcare
}

\author{
Anna Sigridur Islind ${ }^{1,2}$ (D) $\cdot$ Tomas Lindroth $^{2} \cdot$ Johan Lundin $^{3} \cdot$ Gunnar Steineck $^{4}$
}

Received: 28 June 2017 / Accepted: 26 April 2019 / Published online: 20 May 2019

(C) The Author(s) 2019

\begin{abstract}
Healthcare is increasingly permeated with digital platforms supporting cooperative care involving both caregivers (i.e. nurses and physicians) and also patients. New mobile technologies allow for patients to continuously monitor and document their symptoms and gather data that can increase self-care and support the nurse's decision-making process. A design process of such platforms calls for new design approaches involving heterogeneous conditions and goals. Our research is conducted at a clinic that supports cancer patients in their struggles with treatment induced illnesses. The methodological approach is design ethnography that draws from two years of following a design process that resulted in a digital platform to support the care provided by the clinic. The aim of the paper is to analyze how the boundary objects are engaged in the design phases, both concerning what type of boundary objects as well as how they play a role in the different stages of design and we show how boundary objects in design can be used as a mediator for different users' needs and conditions. The research question that this paper explores is: what type of boundary objects can be used, and how are those boundary objects engaged in different design phases during healthcare platform design? We show how different boundary objects come into play during different design phases, from rich narratives, to conceptual formulations and finally into concrete prototypes of the platform. We argue that using boundary objects actively as design tools can inform and forward the design of healthcare platforms and that the approach can guide future design processes, where $c o-$ designing with boundary objects can be especially useful as a design approach when doing design with heterogenous user groups in complex settings, such as healthcare settings.
\end{abstract}

Keywords Co-design - Health informatics - Cancer rehabilitation - Information systems - Designing boundary object . Platformization $\cdot$ Digital platform $\cdot$ Healthcare platforms

\section{Introduction}

All aspects of society are increasingly permeated by digital technologies and healthcare is no exception. Digital platforms in healthcare can enable more patient-centered care where

Anna Sigridur Islind annasi@ru.is

1 School of Computer Science, Reykjavik University, Reykjavik, Iceland

2 School of Business, Economics and IT, University West, Trollhättan, Sweden

3 Department of Applied IT, IT Faculty, University of Gothenburg, Gothenburg, Sweden

4 Clinical Sciences, Sahlgrenska Academy, University of Gothenburg, Gothenburg, Sweden patients are not only consumers of care, but also co-creators and co-producers. For example, digital platforms can allow the patients to collect data about their wellbeing, or about their conditions while at home and transferring the data to healthcare personnel. In that way, the patients can take part in monitoring and adapting their treatments, alongside healthcare making the care increasingly distributed. The patients could also, over time, learn to engage in supportive activities without the involvement of healthcare personnel. The term digital platform, takes into account that a platform is a piece of software while also an intermediary that connects needs with resources and in many cases, sellers with customers or in other cases, users with service providers [1]. A platform is a hybrid between market, firm and a community and a platform is an organizational, technical and regulatory construct that facilitates value creation $[1,2]$. The healthcare platform in this paper, is a platform that connects the patients and nurses. 
The use of digital platforms, transforming care processes, is understood as increasingly important to address major issues in healthcare, such as issues related to increasing number of patients, higher life expectancy due to advancement of medicine, and digital platforms are also thought of as a way of facilitating increased patient-centered healthcare [3, 4]. In parallel to the rise of digital platforms, treatments are also developed in an increasing pace creating a need for tighter coupling between care providers, patients and medical research. The digital platforms created for healthcare purposes thereby have to be designed to support diverse and heterogeneous user groups, challenging previous models for designing digital technologies for care.

The shift towards patient empowerment in clinical practices is an ongoing debate. There are various policy documents and political deliberations where patient centered healthcare is the goal [5]. Still, how patient centered healthcare should be achieved, is not a part of these strategies. As patientcentered healthcare could be designed in general is unclear, it is certainly not clear how a local clinical practice, should increase patient empowerment and, use patient generated health data actively as a part of their clinical work.

Previous research on design for complex practices have focused on processes such as User-Centered Design (UCD) [6] or specific methodologies such as scenarios and narratives $[7,8]$. While this body of work does have a patient-centered perspective and focus on complex design situations, there is a gap regarding emphasize the contemporary platform perspective and heterogeneous user groups and there is also a gap regarding how different design artifacts can come into play during the design process. That particular gap is what this paper focuses on.

When dealing with heterogenous user groups in the design process, the handling of different and possibly conflicting needs and understandings of the desired outcome becomes central, as well as attempting to tie together the different user groups. Creating institutionally closed platforms with no insight for the patient or creating self-care platforms that only the patients have insights into is no longer a viable option and creating platforms that facilitated the needs of both heterogenous user groups, and are a bridge between the two are thereby becoming an increasingly viable option. However, how to facilitate design processes that leads to such platforms and such collaboration are understudied. Let us elaborate. As said earlier, in a design process where heterogeneous user groups are involved, it becomes central to deal with how different agendas and goals are negotiated, as well as how resources supporting such negotiation are constructed and brought into the design process. A large body of literature emphasizes the significance of boundary objects in collaboration across stakeholders [9-17]. A boundary object is an artifact that fulfills a specific function in bridging intersecting practices [17, 18]. An object becomes a boundary object when it serves as a device for transformation, translation, and negotiation at the professional boundaries [9-17]. Boundary objects allow groups to unite and form a working relationship and are instances that enable groups that do not share consensus, boundaries, or professions to consolidate and work together [17, 19-21]. However, theorizing of boundary objects has previously not taken into account how different types of boundary objects come into play in alternate ways during design processes. Also, little attention has been payed to how various types of boundary objects are necessary in different phases of a collaborative process as a means to bring the heterogeneous user groups (i.e. different stakeholders) together and collaborate in highly complex institutional settings on the one hand and on the other hand conducting self-care at home, such as modern healthcare. More specifically, the literature does not fully explain or unpack the negotiation process or elaborate on how different boundary objects can forward the design process and discuss how different types can be explained through the existing theoretical lenses.

The empirical case is a design project conducted in collaboration with research-oriented cancer rehabilitation clinical practice, where patients, after successful cancer treatment, seek care for illnesses related to the aggressive cancer treatment. The clinical practice cares for patients that have severe problems that affect their quality of life as well as their ability to continue with their lives outside their homes. The patients' problems mostly consist of not being able to control bodily functions, as well as dysfunctional sex-life. The patients have however been, declared healthy, because they are cancer free, even though they are dealing with severe problems. Some patients that come to the cancer rehabilitation clinic have complications that will take time to overcome while other complications are permanent issues that the patients have to learn to live with. Because the patients have been declared healthy and are periphery to healthcare, they need to engage in self-care to greater extent, to manage their symptoms or to learn to live with them. This means that a digital platform supporting this practice needs to take into account; i) the clinical and researchoriented practice of the nurses and physicians, ii) the self-care practice of the patients and, iii) the engagement and collaboration between the healthcare and the patients. The aim of the design process was to create a digital platform which would assists all the nurses and the patients separately while also helping coordinate their collaborative efforts. The empirical data is collected from the 2-year long design process of a digital platform.

The aim of the paper is to analyze how the boundary objects are engaged in the design phases, both concerning what type of boundary objects as well as how they play a role in the different stages of design. We suggest that given the dynamic structure of design for heterogeneous users that it can be expected that boundary objects that different boundary objects can be used in different phases of the design process, as the 
design process matures over time. The research question that this paper explores is: what type of boundary objects can be used, and how are those boundary objects engaged in different design phases during healthcare platform design?

\section{Co-design and boundary objects}

The foundational view on design that this paper draws upon is in line with Bergman, Lyytinen [22] where they define design as "a practice of inventing, creating, and implementing (technical) artifacts that depends upon integrates, and transforms heterogeneous and uncertain domains of knowledge." When participatory design, and later collaborative design (which was ultimately termed co-design) emerged in the literature, the design approach was often targeted towards designing a specific service. However, we are not only designing products for, or with, users now; instead we are designing complete future experiences and digital artifacts or platforms that construct cultures and new practices. Doing co-design means involving relevant stakeholders who will later become the users of the digital artifact early in the design process and in co-design, the user is thereby regarded as a partner who actively contributes to the design process. The fundamentals of co-design as an approach thereby entail the users having a voice in the design processes that ultimately affect their lives $[23,24]$. Co-design is more specifically a collaborative, democratic creative activity where users, who are not trained in design work, and designers engage with each other in order to further the design process, which can be seen as a specific instance of co-creation [25].

However, with the abovementioned increased interest in digital platforms, there is a gap regarding the way platforms can be co-designed as previous research has not attempted to apply co-design within platform contexts [1]. The previous literature has focused on platforms that were built for maximal scaling, developed in-house by private companies and designed to become standardized and widespread (ibid). This does not call for user engagement of the same variety as building digital platforms for specific purposes, where the primary goal is not scaling but rather facilitating communication and care between heterogenous users, such as a nurse and a patient [1].

In co-design, the goal is to involve relevant stakeholders, who will subsequently become the users of the digital artifact, early on in the design process [24, 26-29] or in this case, the users of the platform. In more complex situations, where the users consist of more than one stakeholder group, the core of the co-design effort is bridging the prevailing boundaries. The source of boundaries in co-design are rooted in the interface and dynamics among use practices, design practices, and work practices. In these design situations, pre-existing boundaries are embedded in differences related to competence, professions, values, interests, age, social status, or power [25]. More specifically, this approach puts together the expertise of the designers with the situated expertise of the people whose situations will be impacted by the intended change.

The concept of boundaries relies on the idea of communities of practice. A community can be defined by having a specific background and common way of communication [20]. When different communities are interacting, this can be conceptually understood as happening at the cross section at their boundaries. Boundaries may include organizational, social, and/or cultural distances between different stakeholder groups, communities or practices in a collaborative setting. Practitioners need to cross boundaries when collaborating with new and unfamiliar work territories and thereby have to learn how to work with other types of professionals or in new contexts [30]. Doing design together with users that have different backgrounds and domain of interests (i.e. heterogeneous users) raises, what we define as boundary issues. Carlile [13] shows the importance of such collaboration, in terms of collaborative practices that have the ability to span boundaries between different communities. Understanding design processes from this perspective means shedding light more specifically on the mechanisms that tie the groups together or separate them. Akkerman and Bakker [31] discuss how boundaries are becoming more explicit because of the increasing specialization, and new ways of mapping and mobilizing across various cultural and social practices are emerging.

To have practices or different heterogeneous user groups create common understanding in the co-design process, an object or a representation of a thought can be vital. Within the research focusing on aspects of communities and their boundaries, boundary objects denote when an artifact fulfils a specific function in bridging between intersecting practices $[17,18]$. A boundary object is an artifact that fulfills a specific function in bridging intersecting practices [17, 18]. An object becomes a boundary object when it serves as a device for transformation, translation, and negotiation at the professional boundaries [9-17]. Boundary objects supports the collaboration and forms a foundation for a working relationship and are instances that enable groups, that do not share consensus, boundaries or professions, to consolidate a knowledge boundaries between different collaborating expert groups $[12,13]$. More specifically, a boundary object is an artifact that has different roles for different groups that might have boundaries between them. Boundary objects enable groups to come together and form a working relationship and are thereby objects that allow groups that do not share consensus on beforehand, or have boundaries between them, or are from within different professions, to consolidate, find common ground and work together [17, 19-21].

Boundary objects are thereby the links in the communication processes where different perspectives are to be 
negotiated and discussed into a co-created meaning and consensus. What then is needed to make this happen is models and applications, which can serve as boundary object systems to support knowledge sharing and co-creation of meaning [11]. Boundary objects play important roles as shortcuts to communication, as well as playgrounds for knowledge sharing among different communities of practice [20, 32-35]. Although, boundary objects can only facilitate parts of the communication surrounding a boundary object and due to that, cannot replace communication and collaboration [31]. Boundary objects are often technological artifacts but can be other things that binds professions or stakeholders; such as drawings or prototypes $[10,36]$, repositories, standardized form or workflow matrices [15], but can also be on a more abstract level, such as processes or methods [37], metaphors [38] or narratives [11]. Boundary objects have been studied in various contexts where different kinds of artifacts have been conveyed as boundary objects. Among these studies are studies within museums [17], using engineering drawings as boundary objects [12, 39], aircraft maintenance requests [40] as well as medical patient records as boundary objects [41].

Emergent boundary objects are often derived from complex wicked problems and begin in design concepts that continuously change and evolve during the design process [42]. Emergent boundary objects are therefore boundary objects that have not yet been stabilized and are still being negotiated according to Dalsgaard, Halskov [42]. In accordance with Ewenstein and Whyte [43], they can also be seen as open boundary objects. Open boundary objects can especially be applicable as a concept where non-artifacts are seen as boundary objects $[17,19$, 43]. The distinction made by Ewenstein and Whyte [43] between open and closed boundary objects has grounds in Leigh Star [19] distinctions "between the "ill-structured" use of boundary objects between social worlds and more specific "tailored uses" within those worlds" [19, 44].

Reflection and communication over action is, according to Boland and Tenkasi [11], driven by narratives. Narratives are a carrier of both reflection and communication between communities of practice (ibid.). By turning experiences into narratives, people rationalize their experience, making them rational and believable. Narratives are thereby a way of seeking ongoing coherence of actions while being in the middle of a practice. In situations where participants with contradictory perspectives are collaborating, common narratives are Boland and Tenkasi [11] means for boundary crossing to happen but also harder to coconstruct. Narratives as boundary objects might therefore facilitate perspective making in and between communities of practice [11]. Koskinen [38] suggests metaphorical boundary objects to have an important role as co-ordination mechanism within knowledge sharing processes. It is especially relevant to consider this type of objects when studying emergent knowledge processes where new knowledge and understanding emerge as a result of innovation activities. Koskinen [38] argues that metaphoric boundary objects are relevant because with them, companies can create the necessary shared understanding and framing of the emerging problem in innovation activities. Koskinen claims: “...in contrast, when a boundary object is strongly structured, it can function as a co-ordinating mechanism in explicit knowledge communication. In sum, what a boundary object gains in structure, it loses in creativity and tacit knowledge communication." [38]. What Koskinen suggest is a tension between different type and qualities of objects. Thus, a more concreate and externalized objects does not necessarily mean a better object (ibid.).

\section{Research approach}

The aim of the study is to investigate and understand the function of boundary objects within a design process. Because the design process is the unit of analysis in this paper, design ethnography has been the guiding methodological approach of this study.

When studying design of information systems, there is a long tradition of ethnography for design and its discount derivatives [45-47]. The aim of design ethnography (DE) as a method is to contribute with a shared design experience to facilitate learning about social and cultural practices and values, from the empirical case. DE is a research approach where the researcher is actively engaged with others with future oriented objectives "designing, creating, innovating, and improvising artefacts" that may affect the cultural and social setting [48]. Additionally, the ethnography is not conducted before the design process begins, instead, the design process is the ethnography and the researcher is doing participatory observations from within the design project [48]. In contrast to traditional ethnography, within $\mathrm{DE}$, the researchers have an active role and are engaged in the design process, while designing artifacts, and that was the case within this research initiative. Generating a novel artifact is an important step in the design ethnography as a methodology but it is not the main contribution. The contribution is the learning and knowledge about the isolated design experience within the specific practice, its stakeholders, goals, and action space and turn them into more generalizable design values.

\subsection{Data gathering and analysis}

The first and second author of this paper collected the empirical data. The third and fourth author participated in the analysis of the data. The first phase (grey in Figs. 1 and 2) included forming the project group by mapping competences with people that could be included in the project group as well as negotiating of overarching project goals and form. The clinical context became a part during that time and initial interviews were done both with the founders of the clinic, the nurses and the patients. The interviews were semi-structured and followed an interview guide and the interviews were recorded and transcribed and the 


\begin{tabular}{|c|c|c|c|}
\hline Phase & Data gathering method & Duration & Aim \& participation \\
\hline $\begin{array}{l}\text { Work in-between; } \\
\text { phase } 1\end{array}$ & $\begin{array}{l}\text { a) } 3 \text { Negotiation meetings } \\
\text { b) Project vision } \\
\text { c) Staffing and funding of the project } \\
\text { d) Negotiation with stakeholders in } \\
\text { elinical practice } \\
\text { e) Field specific presentations }\end{array}$ & $\begin{array}{l}3 \text { hours } \\
64 \text { emails } \\
3 \text { hours } \\
2 \text { hours } \\
2 \text { days }\end{array}$ & $\begin{array}{l}\text { a) Meetings to negotiate the project's content; } 9 \text { hours in total b) meetings on a } \\
\text { regular basis as well as email contacts c) Negotiation where the clinical practice } \\
\text { and the researchers were trying to find common ground and establish a arena for } \\
\text { collaboration d) negotiation with the clinical practice regarding research access e) } 2 \\
\text { day meeting to inform the multi-disciplinary research context of the interest of the } \\
\text { other fields, the fields were IT, medicine, nursing \& pedagogy. }\end{array}$ \\
\hline Snapshot 1 & 1 Future-oriented workshop & 3 hours & $\begin{array}{l}\text { b) Future-oriented workshop with representatives from the nurses, patients, the } \\
\text { researchers and the developers. }\end{array}$ \\
\hline $\begin{array}{l}\text { Work in-between; } \\
\text { phase } 2\end{array}$ & $\begin{array}{l}\text { a) } 9 \text { observations } \\
\text { b) } 7 \text { information workshops } \\
\text { c) } 3 \text { patient meetings } \\
\text { d) } 3 \text { patient interviews } \\
\text { e) Infrastructure for collaboration }\end{array}$ & $\begin{array}{l}1 \text { day } \\
1 \text { hour } \\
1 \text { hour } \\
1 \text { hour } \\
4 \text { hours }\end{array}$ & $\begin{array}{l}\text { a) Overt non-participant observations for } 9 \text { days total to get full grasp of the nurses } \\
\text { workdays b) These workshops were done to get the information portal up and } \\
\text { running c) Three observations of face-to-face patient-nurse meetings at the clinic } \\
\text { d) Interviews with patients from the clinic as well as one patient representative } \\
\text { that has had cancer in the past but has had no ties to this particular clinic } \\
\text { e) infrastructure for collaboration between the researchers set up and negotiated. }\end{array}$ \\
\hline Snapshot 2 & $\begin{array}{l}\text { a) } 3 \text { role-playing sessions } \\
\text { b) } 6 \text { wireframes and goal } \\
\text { formulation workshop }\end{array}$ & $\begin{array}{l}3 \text { hours } \\
2 \text { hour }\end{array}$ & $\begin{array}{l}\text { a) The role playing sessions' aim was to imitate the nurse-patient conversations } \\
\text { (called nurses as proxies) for personas and UX design. These sessions were three } \\
\text { three hour sessions; in total nine hours b) } 6 \text { workshops / focus groups where goal } \\
\text { formulation and wireframes were negotiated with the nurses. }\end{array}$ \\
\hline $\begin{array}{l}\text { Work in-between; } \\
\text { phase } 3\end{array}$ & $\begin{array}{l}\text { a) } 5 \text { design sessions } \\
\text { b) } 5 \text { observations of video-meetings } \\
\text { c) } 5 \text { patient interviews } \\
\text { d) Boundary object discussions }\end{array}$ & $\begin{array}{l}1 \text { hour } \\
1 \text { hour } \\
1 / 2 \text { hour } \\
2 \text { day meeting }\end{array}$ & $\begin{array}{l}\text { a) Design session where the software developers met with the nurses b) Five } \\
\text { observations of video-meetings between patients and nurses } c \text { ) Interviews with the } \\
\text { patients that were involved in the video-meetings } d \text { ) Two day meetings where the } \\
\text { material is partly used to illustrate the snapshot, whereas some of the martial was } \\
\text { more project related or related specifically to patient problems, not specific to the } \\
\text { boundary objects. }\end{array}$ \\
\hline Snapshot 3 & a) 2 Workshop & 2 hours & $\begin{array}{l}\text { a) Workshop with concrete objects / prototypes, } 2 \text { in total with the nurses, each } \\
\text { one } 2 \text { hours making the material } 4 \text { hours in total. }\end{array}$ \\
\hline
\end{tabular}

Fig. 1 The data gathering activities and duration

observations were documented with observations notes. The workshops were documented via audio-recordings, that were transcribed and also with observation notes.

The second phase (blue in Figs. 1 and 2) included a traditional qualitative study of the existing clinical practice where three user groups were identified; i) the nurses, ii) the patients and, iii) the physicians whereas this paper primarily focuses on the first two. The phase also included developing personas based on the aforementioned user groups. Personas is method for enhancing user experience in the design process $[49,50]$ and the personas will be described in more detail in the results section. During this phase, the expectations and goals were mapped and the desired outcome was mapped out and identified with various design and user experience methodologies. These personas and maps were then used, iterated and improved throughout the design process. During this second phase, consultations between a nurse and a patient were observed to obtain in-depth understanding of the clinical setting.

The third phase (green in Figs. 1 and 2) focused on design goals. By conducting workshops and by conducting overt non-participatory observations a set of design goals were collectively decided upon. More consultations were also observed but herein they were conducted via a video-mediated consultation tool. In the third phase the design and development of the platform started. It was during this phase of the process that the overarching design values were formulated.

The material was analyzed through interpretative thematic analysis e.g. [51] where the boundary literature was influential. The first author did most of the work with the analysis but the latter three authors did contribute to the analysis phase by looking at the data together with the first author and the authors discussed iteratively. The findings of the analysis were presented and discussed with the nurses and the rest of the project team. The boundary concepts were used as an analytical tool to study the boundary objects and their role in the design process. The empirical material is based upon three design phases. The data gathering activities within each phase is illustrated in Fig. 1 below. Three specific snapshots were selected to illustrate the boundary objects (see Fig. 1 above and Fig. 2 below) as they represent the work-in-between that had taken place before and the snapshots were in that way, a summary of the work that had taken place in the phase and as a closure of the phase, to capture the essence of the phase. This process of formulating, negotiating and co-designing these design objects; the boundary objects, the boundary work in-between and the three snapshots construct the essence of the empirical results that this paper presents. Note, all empirical data has been translated from Swedish to English.

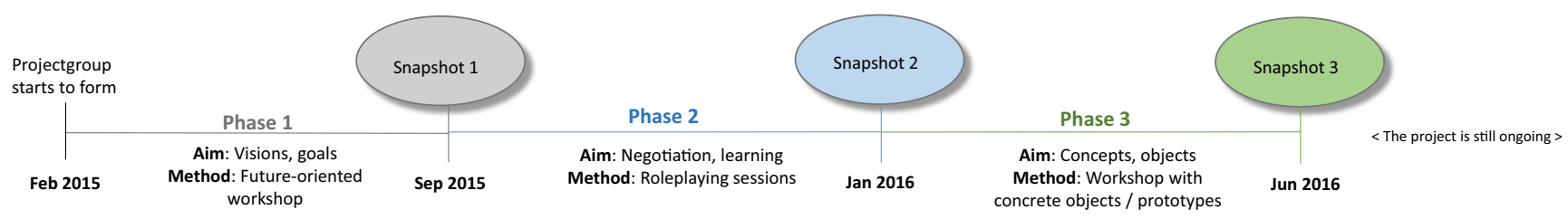

Fig. 2 The three phases 


\subsection{Empirical setting \& the co-design process}

The clinic is located in West Sweden. The care offered at the clinic is highly influenced by research and the clinic is mostly funded by research funds. The number of patients being cared for are around 200 a year. Some patients come often, some once and there are even patients that never come, but call the clinic for telephone consultations. Some patients come directly after their cancer treatment, others' years later. The average patient is in contact with the clinic for between six months and two years. Four people work at the clinic; one physician specialized in oncological cancer and three nurses that are all licensed practical nurses and specialized in oncology. Additionally, there are other experts linked to the clinic. These specialists can be referred to by the nurses and the physician and include dietician, psychologist, a specialist in lymphedema and diverse specialists that can help with specific patients.

The cancer types that this clinic specializes in is cancer in pelvic area; ovarian cancer, cervical cancer, endometrial cancer, prostate cancer, rectal cancer, anal cancer and bladder cancer. The cancer treatment has been necessary but results in some patients having urinary leakage or fecal leakage where the severity varies. Most people are obviously relieved when they survive their cancer but with these kinds of complications, there is not an easy road ahead. The patients come after their fight with their cancer is over and have a consultation with a nurse about their life post-cancer. The patients either find the clinic on their own or through contacts or have a referral from physicians. Consequently, the first contact varies from either being taken by the patient or by the nurses after receiving referrals. The patient is offered appropriate care (in most cases a physical meeting) but first, as an initiator of care, the patient answers a comprehensive baseline survey that is mailed out via regular mail. The professionals within the clinical practice consists of specialized nurses that have years of experience and are experts in such care. The nurses guide the patients in getting to know their new body (post-cancer) by giving advice, as well as grounding medical decisions with medications and referrals to physicians or other specialists.

The co-design activities have been conducted with the nurses and the patients at the clinic. This co-design process resulted in building a platform as a complement to the regular care that already takes place at the clinic. The boundary objects, discussed in the findings and discussion, are the grounds on which the platform is based upon and the design process reported on herein has fed into the iterative platform design. The boundary objects were used actively to forward the design process and even though they were not called boundary objects per se when discussing with the nurses and the patients. They were called design objects and they were used to find common ground during the design process. However, the boundary objects literature was a part of the study design from the beginning and the authors of this paper were highly influenced by thoughts from the boundary objects literature so when introducing and using the different boundary objects, that had a variety of maturity level, they were talked about within the author group as boundary objects (and referred to as i.e. narrative boundary objects in the first phase, elaborated below).

The platform that the co-design process resulted in was a collaborative platform. The patients collect data through a mobile app (see [52]) that logs defecation and urination frequency and consistency. The data from the digital artifact was incorporated into the platform (in a secure site where login is required) and visualized so that the nurse and the patient can both access it. The patient can access their own data, see the patterns as well as video chat with the nurses. The visualization of the data, as well as the video-mediated consultation tool and a text-based chat were side by side, which meant that the nurse and the patient had the same view, at the same time during the consultations and could make sense of that patient generated health data together. Consequently, they could either take the point of departure from the data or from difficulties that the patient were dealing with during their consultations and use the visualizations of data as a support. One outcome from the design process was also creating an information portal (front-end of the platform) for the patients to access information to feed their self-care process which also functioned as a tool for the patients to prepare for the consultations at the clinic.

\section{Results}

In the following text the abovementioned design iterations are described in three phases in the process towards the emergent boundary objects and is structured in accordance with Fig. 2, in a chronological order of the phases, where the boundary work in the phases is illustrated and then the snapshot presented. Throughout this section, the results will be presented first and then followed by short summary of each phase before moving on to next design phase and snapshot.

The first phase (grey) is herein called connecting through patient stories, the second phase (blue) is called working with design goals and the third (green), is herein called using prototypes.

\subsection{Phase 1: Connecting through narratives}

In the first phase of the co-design process the different stakeholders shared stories describing central aspects of each 
other's practices. In particular the work involved sharing patient stories to gain in-depth understanding into the patients' problems and their way of life.

The patients are dealing with variety of problems such as in this excerpt from a patient with anal cancer: "Received chemotherapy 90 hours straight and radiation for 30 days in a row except Saturdays and Sundays November 2013. My stomach is upset and can only go to the bathroom 1 times a week, but the worst part is that I was completely burned both front and back and still have sores that usually bleed and hurt. My skin is so thin and fragile. Wondering if there's anything that can make skin stronger and thicker?"

Understanding the severity of the everyday life problems of the patients, was important in the design process in two major senses. Firstly, the main purpose of the whole healthcare process is to support and treat the patients, this is central. Secondly, the patients' involvement was a challenge since they participated very much as private individuals and not professionals. They had also been declared "healthy", meaning that they were expected to go back to work, consequently, the patients had significantly less time to take part in the design process.

Another patient story is: "I underwent radical hysterectomy, radiation and chemotherapy treatment for vaginal cancer in autumn of 2015 (I was 51 years). Since my surgery, I have not been able to urinate without a catheter, an iatrogenic disability that I feel is extremely limiting. In addition, I have the "normal" bowel problems and problems with sexual function and lymphedema as many seem to experience. It should not be like this for us patients, it is already a challenge to survive and we should not be so alone with all the consequences of the disease / treatment. Is there a discussion forum for patients where we can support each other and share our experiences in? If not, I would suggest it - the loneliness is almost the worst of it all, especially with some rare forms of cancer."

As illustrated in these two example the patient's problems typically are their focus and the care needs to be personalized and individual. The patient stories, were collected through the platform. The phase also included a workshop / focus group where the aim was to construct boundary objects that could be a guide forward in the design process and to capture the complexity as well as the different user goals. To be able to co-design the platform that would function as a facilitator of self-care for the patients and working tool for the nurses, there was a fundamental need to understand each other needs.

The nurses also described how they typically engaged with the patients: When preparing for the patient meeting, the nurse reads the patient's electronic journal as well as the baseline survey. In the physical meeting, the nurse goes through the baseline survey with the patient to see if something has changed since answering it and asks questions that are grounded in the answers from the baseline survey. Sometimes the patients answer the baseline survey and then weeks pass before the physical meeting so that their symptoms might have changed during that time. This is especially relevant for patients that have received cancer treatment recently that could affect symptoms (i.e. defecation frequency and nausea). The conversation leads to selecting the most difficult symptom, and then focuses on solving that. The physical meeting is followed by telephone consultation. Then, when that symptom is somewhat under control, they move on to the next symptom, which may require another physical meeting.

The narratives were used to develop common sentences that acted as goal formulations for the design. The participants also could provide feedback on these, relating them to their respective practices. For instance: "balancing use of existing technological artifacts with realistic expectations of adoption." This goal is fairly hard to grasp and is on high abstraction level, this one is also abstract: "find a way where we can develop step-by-step models to be able to conduct continuous studies and iterations in the design process." The visions of "developing healthcare that takes responsibility for early and late complications" alongside the vision of combining "good patient contact, competences, technology and relevant content" are large scale, highly abstracted visions that were a part of the first snapshot. The long patient stories and the high abstraction-level clinical goals were used as guiding tools to deepen the understanding in the design process as they shed light on the patients' life and the clinical practice separate requirements that needed to be facilitated in the platform.

As the research group is multidisciplinary collaborating with the clinical practice, the shared understanding of the work through the nurses' and patients' thick descriptions and goal formulation was a vital part in forming a design practice to gain common ground. Through the analysis of patient stories such as those illustrated in the examples, it became clearer that the patient's problems and the nurses work are complicated and digitalizing aspects of the caring process (i.e. designing the platform that could support the care) was both a delicate and complex task.

\subsection{Phase 2: Working with design goals}

The design work during phase 2 , involved digging deeper into and observing the clinical practice to gain more understanding of the users' needs. In this phase, personas were developed as a way of forwarding the design process (see Fig. 3).

The figure above is merely illustrative, to show the results of the personas, the personas are however in Swedish and due to that, they are blurred. The personas were developed to find a way of illustrating the heterogeneity of the 

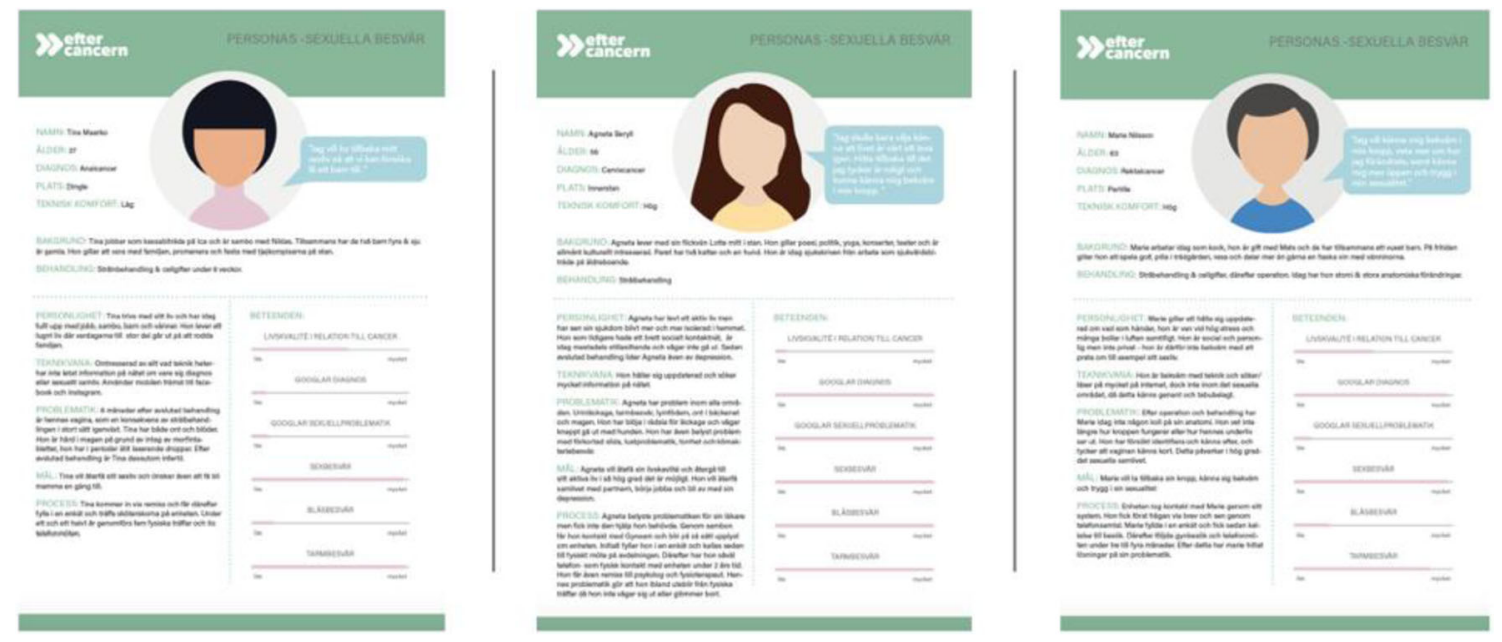

Fig. 3 Personas

patients and were developed with the nurses, as an exercise in finding out what type of patients we were dealing with. The design method herein was called design by proxy Islind et al. (forthcoming). The project members also increasingly developed goals that would guide the design. The understanding that the narratives had established, created a foundation upon which collective goals could be formulated.

In regard to the narrative from the patient that had urinary, defecation and sexually related problems, increasing the reach to enable these patients to stay at home or if they work, at work was a design goal that became a central one. "Increase reach, both in a geographical sense and in a mobile sense. Gaining both reach into the patient's everyday life, their homes and reach to new groups of patients, outside of the region." This would decrease travel, which is important because travelling limits the closeness to bathrooms. This goal thereby included patients that are unable to leave their homes, patients that live outside of the region and patients that today do not know of the clinic's existence was a goal that became a central one. While working towards the reach, the vision of designing the video-mediated consultation tool as a part of the platform, became a priority.

If the patient is occupied with fecal leakage one cannot expect them to remember everything that was said during the consultations. However, it is not only about remembering as this goal also considers the access to the right information at the right time. Some of the patients spend several hours on the toilet every day and not always at home. The thick binder with medical information that they have gathered during consultations is not always available. The goal of: "Decreasing repetition and increasing the ability to self-care with accessible information." The goal is to provide continuous access to the different tools that are offered by the clinic. This goal also decreases the load on the nurses' shoulders to repeat information. The implication of designing an information portal as a part of the platform where the patients could seek information in dire need, became a prioritized path to work towards facilitating this goal.

The third goal was formulated: To increase patient's involvement with self-care tools. With functions that actively involve the patients, there is also a chance that they will increase compliance and increase the likelihood of completed exercises and tasks that have been agreed upon with the nurses during consultations. The importance of gathering data with wearables and logging of toilet visits that would feed into the platform through an app, would give both the nurses and patients more reliable data and became a prioritized part of the design process.

Even though the patients live with their conditions every day the relationship between causes and effects/symptom have proven to be too complex to grasp without further augmentation. The fourth goal was therefore: "The complexity of the problem situation and the relationship to the cause." The patients and the nurses have asked for assistance in identifying cause/effect patterns. Being able to measure the patient's real activity, takes the responsibility of estimation and guessing of the patient's shoulders. Both the patients and nurses asked for more reliable data about everyday activities in order to enhance the decision support so visualization of the patient data from the app and wearables became a vital part of the design process.

In regard to the patients stories about the urination and defecation frequency problems after the cancer treatment, there is both need for education and empowerment. Helping the patients balance the frequency, is a large part of the nurses work as well. Some patients need medication but others need information and tools to feel empowered and in control. The fifth goal was: "Increasing self-efficacy, empowerment and independence." To make some of the patients more independent and less reliable on the nurses and healthcare in general there is a need to increase the patient's self-efficacy. The 
patients are the real experts of their own condition which needs to be acknowledged and communicated in the design solutions. In order to empower the patients, they need to be self-sufficient when it comes to information, data collection tools as well as analytical resources. As a part of getting there, the importance of the platform as a whole, both as a self-care tool and as a working tool, was the main focus of the design process.

In regard to the patients story about the frail and thin skin and after the cancer treatment, there is a need for a caring tone. The sixth and last goal of this phase was: "Preserving the caring tone in the physical meetings [i.e. the caring conversations] between nurses and patients." To preserve the gentle relationship between the two it is of great importance to carefully design for the right tonality. There is a concern among the patients and the nurses and a general risk that an increase of technology in the clinical practice will decrease the social interaction between the nurse and patients. To counter this risk, it is important that the language, choice of words, the tone of voice and the aesthetics of the information in the information portal, as well as the tonality in the video-mediated consultation is in line with caring conversation in the face to face consultations.

Using these goals as a part of the design process, functioned as boundary objects, between the multidisciplinary research context and the clinical practice to find consensus and negotiate further. The patient stories were still a part of the design process but during the design work, they moved from the foreground to the background and the design goals became of more importance.

\subsection{Phase 3: Communicating through prototypes}

In the third phase the design team had established a collective foundation with the narratives, formulated goals and were able to start designing the concrete platform. In the process a variety of prototypes were used to further explore the practices, as well as to guide the development of the platform.

The visualization of data was utilized as high-fidelity paper prototypes (mock-ups) visualizing the patients' defecation frequency and medication intake. During a workshop / focus group at the clinic, three nurses and researchers from the multidisciplinary research group were involved in a discussion revolving around the paper prototypes. The prototype triggered an increased understanding of the possible utility of the visualizations.

For the frequency, a mobile app has been developed alongside a Bluetooth button that the patient's push every time they use the toilet. Once for urination, twice for defecation. The app is prompted by the push of the button and the app asks questions concerning consistency and related factors. The app reminds the patients' about taking their medication and keeps track of that as well. When talking about measuring the patients to gain precision, as well as reminding them of taking their medications, the nurses see positive aspects in that: "This is a lifelong medication that [the patient] must take at least in this specific doze, during the bad periods, you will have to take more. So mapping this over time could strengthen these assumptions and for also those that have bacterial overgrowth. Those [patients] who need penicillin periodically can see the frequency going up and maybe they note something about the consistency. The consistency maybe changes with about two months' interval and then [the patient] needs penicillin. Mapping that would show that, ok, this is what we can expect in the future." However, there is another side to the mapping that the patients have expressed. The patients do not want to be constantly reminded of their sickness when they are in fact cancer free, even though they are dealing with lifelong complications due to their cancer and the cancer treatment that they have received.

While discussing how the patients measure their defecation and urination frequency there are a number of different strategies. The nurses usually use specific tables for these problems that the patients fill out during two whole days. They have, however, had some patients that have measured for a longer period of time. There are some problems with just measuring for two days, when talking about a patient that documented their bodily functions for four months they say: "That lead of course to us actually seeing what the problem was. It is not optimal with just two days of measurement. Because, you can get an active and a more passive day but you cannot see in general how it is normally. You get influenced by what you measure, you might adjust a little in your drinking habits. But measuring over long time, it eventually just becomes a routine. So it becomes more of a fact on the patient's real problems. If you have the energy to keep up with a measurement for such a long time, then it's a huge value. On the other hand, if we would have known that she has these problems, we would have done something, and then it had not been mapped." There are of course some dilemmas with measuring for such a long time without helping the patient and because the measurements are analog the nurse has no way of knowing how severe the problem is but with live data, the nurses can help the patients much sooner. "I have high hopes for the [platform] for logging because I think that must be much easier than documenting on paper. But some will prefer documenting on paper anyway, because we are all different." The prototype was to trigger conversation about how to visualize the gathered data in the digital artifact. The patients and the nurses use the data together in their consultation).

Another prototype was discussed, a video-mediated consultation tool (a digital artifact, not a paper prototype) that is one aspect of the platform that was being developed at this time and the nurses had tested a prototype: "This puts pressure 
on the technology and our digital competencies." Another nurse replies: "Yes it cannot be any hang ups. We need to get better at the technology." They continue: "I sat yesterday and nothing worked namely, when we said we would have a video chat with a patient. I did not get her sound to work with ours. And also, there is need for development regarding how it looks, it needs to look more professional in my opinion." The patients have also been testing the same video-mediated consultation during this phase: "I think it's awesome and very good, because then you do not, what should I say, you don't have to meet so you just turn on the computer. Then there is no travel time involved." When discussing the video after a video-mediated consultation another patient says: "Well yes, I thought this was good, nice solution. People are not always able to travel to the clinic and then the telephone is really good, however, it is like another kind of contact when you are able to see each other."

The nurses reflected on their participation in the design process on describe how it has opened up for other aspects than merely the design of the platform and digitalization of care: "This is really good, for the way we work. Partly because of the knowledge sharing and because we do things [conduct the caring conversation and care work] so differently. Knowledge exchange, like these small sessions, we should have. You take it so for granted that you do everything like, well, like I do. But of course we do things differently. I think we actually work quite differently. So it is great to sit down like this. I know the other times we've sat down together as well, allows for us to give each other tips." Another nurse replies: "Yes, it's great. Even if we meet often we do not actually talk this way. This is healthcare development. And learning. Really. More workshops in healthcare!"

The work during phase 3 was more in forms of systematic design work as the collaborating design practice had formed more strongly and the shared visions were becoming clearer. Snapshot 3 had traditional sense and during the workshops / focus groups the prototypes were used to advance the design process. Using the prototypes as boundary objects triggered fruitful conversations both concerning the design as such, but also about the use of the platform in the future as a part of the care at the clinic. The design process could move forward and the software development of the platform continued in a rapid agile manner.

The project, after this, continued to develop the platform and it is being used by the nurses as a working tool and by the patients as a way of facilitating their self-care and everyday logging of their symptoms. We have continued to follow this and are still an active project where we for instance have focused on the implications of data work of the patients and the nurses $[52,53]$ also on the affordances of different ways of mediating consultations [4], as well as other related papers. The project as such is in its fourth year whereas this paper presents the first two years.

\section{Designing with boundary objects in clinical practices}

Building a bridge between heterogonous user groups, such as nurses and patients, in a design process calls for a delicate design approach. The history of failed information systems implementations in healthcare which have been pushed down the organization in topdown manner (such as electronic patient records), also tends to nurture more resistance towards digitalization in healthcare [54-57]. The failed implementation attempts, has at times triggered what we here want to call posttraumatic digitalization stress disorder and resistance in some healthcare practices. To handle this resistance and history of failure also means that design processes within healthcare, need a more sensitive approach where both the clinical practice and the patients' needs should be considered and co-designing with boundary objects, could be one such approach which fits healthcare settings.

The above illustrated case is an instant of such a design process. The different boundary objects come into play in different phases which is illustrated by the journey of the boundary objects evolving from open to closed, from unstructured to structured. We argue that using narratives to form a collaborating boundary practice, then moving towards metaphorical boundary objects and at last towards structured boundary objects can be beneficial in design processes within a highly institutionalized and complex work environment, such as in healthcare. In the following section we will discuss how the theoretical lens of boundary objects is not only an efficient analytical tool to understand heterogeneous user groups but also that using them actively can be an efficient co-design approach.

Using the three forms of boundary objects, in the three phases, did not merely serve as a bridge between the nurses and the patients but also as a representation of needs that was essential for the multidisciplinary research group (i.e. designers) to understand the clinical practice together with nurses and patients. The negotiations where the goal was to find consensus in each design stage were augmented by the boundary objects. By doing co-design we have involved the stakeholders who later became the users of the digital artifact early in the design process. The method we have applied, and would like to offer as the main contribution of this paper, co-design with boundary objects, bridges the pre-existing boundaries rooted in differences related to competence, professions and values (to name a few). The approach also handled the inevitable challenge in co-design projects to combine the expertise of the designers with the situated expertise of the user groups. 


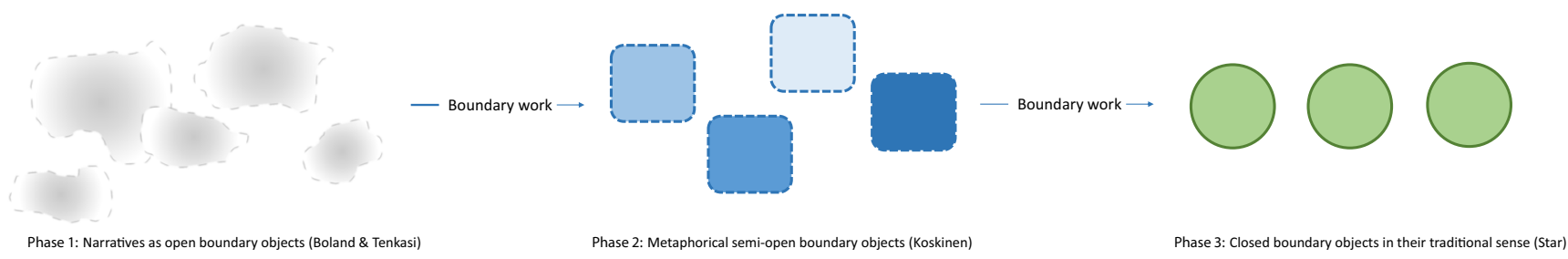

Fig. 4 The boundary objects

\subsection{From narratives to structured boundary objects}

Below we describe the three phases (visualized in fig. 4) and their design role. The final sections summarizes the role of boundary object in co-design.

\subsubsection{The narrative phase}

In the beginning of the design process, the boundary objects were stories in the form of narratives. The boundary objects were unsophisticated and not summarized into well distinguished objects with clear cut demarcations. This is in accordance with how Boland and Tenkasi [11] use narratives as boundary objects. The narratives, in the forms of patient stories, played a central role for understanding the patient group and the healthcare professionals as the needs of both user groups needed to be accommodated for. The patient narratives conveyed, in an unstructured form, the central aspects of being a patient. In a way, the narrative became the container of the essence of being a patient. Additionally, these unstructured boundary objects produced highly abstracted visions among the project participants. Thus, the narrative boundary objects assisted in the formation of a mutual understanding and common ground in the platform design process [30]. The boundary objects were open, open because they opened up the design space and giving rise to more questions rather than answers. Open boundary objects are however, ill-structured, open ended objects that raise questions and create a dialog instead of being a well-structured solution. Hence, typical characteristics of early phase boundary objects. These open boundary objects are of help in evolving and raising questions about some aspects of the design process while also stabilizing other aspects [43].

\subsubsection{The metaphorical phase}

During the second phase of boundary work, the boundary objects grew. From negotiations around the narratives, design goals emerged, such as "Increasing self-efficacy, empowerment and independence." Goals that are still rather undefined from a solution and technology perspective but still concrete enough to break down and asses at a later stage. They were more in sync with user goals and a boundary spanning collaboration practice was more apparent $[12,13]$. As in the example above, "independence" refers to the relationship between the patient and the nurse with a clear aim to strengthen the patients position in order to create a more balanced collaboration. The design goals were more concrete like the boundary objects in terms of Koskinen [38], metaphorical boundary objects. However, the boundary objects were still open boundary objects, [43], not fully developed, but still more mature compared to the narratives. By open, we mean open for interpretation by the different actors (patients, nurses and designers). By "not fully developed" we compare them to functional requirements lists, wireframes of graphical user interfaces, user stories or technical solutions.

As illustrated in the findings, some of the metaphorical boundary objects had to do with evolving healthcare in general and others had to do with the specific caring conversation and consultation at the clinic in particular. The metaphorical boundary objects were also what the collaborating co-design practice could find consensus around. These wishes for the future practice was characterized by being goal-oriented, vision-oriented, practice-oriented and possible to assess.

\subsubsection{The structured phase}

To bring the design process forward, more structured boundary objects [19] were introduced in phase 3, represented by the shared prototypes which were used actively. Using the structured boundary objects, in terms of prototypes, triggered more conversation about future functions of the platform. Koskinen [38] metaphorical boundary objects were still there, as they formed the basis for the more structured boundary objects. The co-design process was ready to move forward and the more structured boundary objects was slowly introduced. The metaphorical boundary objects were therefore backgrounded and the prototypes in terms of more structured closed boundary objects, brought forward.

With structured, we mean elaborated, concrete and close to a real solution. Closed refers to the experienced rigidity of the mockups, that they are experienced as more real and not as easy to change. Closer to the final solution. This is particularly visible in the discussion between the nurses as it triggers a range of discussion topics. Topics including the difference in how they work, the problems of visualizing measured patient behaviors. Topics that, according to our experience, would not emerge with the less concrete boundary objects. 


\subsection{The role of boundary objects in design}

Nicolini, Mengis [15] examine the role of objects in general (i.e. boundary objects, epistemic objects, cultural historical activity theory and infrastructural objects). As in this article, they propose a pluralist approach where each theoretical lens has merits depending on the context of the use as each lens holds unique characteristics [15]. However, their study puts objects of different characters in focus, while we have dug deeper into the specifics of the boundary object lens. We propose a pluralist perspective of boundary objects and calls this design approach co-designing with boundary objects. An approach where we suggest different types of boundary objects during different stages of the design process. More specifically, where different theoretical standpoints from within the boundary object literature can be used to advance the design process in different phases, depending on the maturity of i) the collaboration and ii) the design process. As the design process advances, the boundary objects have a range of functionalities and characteristics. It is central that the coupling between the need for creativity and structure in the design project is match by the boundary objects used in the design approach. The previous boundary objects are not replaced but are however backgrounded and the new ones, needed for the phase at hand, are instead foregrounded. Figure 4 illustrates the design process and that different boundary objects are called for, at specific times to move the collaboration and co-design process forward. The approach is especially relevant when designing for emergent knowledge processes and innovation activities.

The non-artifact ill-structured boundary objects $[17,19]$ in phase 1 and 2, were open boundary objects whereas the boundary objects in phase 1 were more open than in phase 2 [43]. However, in phase 3, there was a need for some more structured prototyping, moving towards Leigh Star's [19] tailored use within the social worlds of the design process, resulting in the use of more closed, structured boundary objects [19, 43, 44]. The emergent properties of the boundary objects can therefore be seen as moving from open to closed over time. Linking the theoretical standpoints from the boundary objects literature, can be of use for other design processes. Co-designing with boundary objects, as an active choice during the design process, especially when designing with heterogenous users can be an approach for others as well. As design projects with focus on digital artifacts tend to have a rapid agile tone to them, using boundary objects to guide the process forward, can be a viable choice. Using structured boundary objects [19] directly from start, would not have been preferable in this particular design process due to the multidisciplinary aspect of the collaborating boundary practice as well as the complexity of the nurses work and the patient's life situation. Using narratives to form a collaborating practice, then moving towards metaphorical boundary objects with time, can especially be beneficial in design processes within healthcare where complexity is high and the institutional and regulated environment calls for a more delicate design approach. The boundary practice needed time to grow and create consensus and the boundary objects have both strengthened the boundary practice while also strengthening the boundary objects. Designing with boundary objects might slow down the design process initially but actually speed up the programming process as fewer aspects will come as a surprise during the software development, when everything has been negotiated thoroughly on beforehand.

\section{Conclusion}

Healthcare is increasingly permeated with digital platforms supporting cooperative care involving heterogeneous user groups. The successful design of such multi-user platforms calls for new design approaches. Our design process resulted in a successful platform design, as the platform is now being used as a part of the clinical practice and as a part of the patient's life. We argue that understanding such a transformation can inform the design of healthcare platforms, as well as guide future studies of design. The theoretical lens of boundary object is an efficient perspective, both scientifically to analytically describe and understand a complex practice but also when designing for such a practice. While others have examined the role of objects in general, we examine the role of specific types of boundary objects, for different phases in the design process. The paper shows how what type of boundary objects, and when those different boundary objects are needed in different phases of the design process, from rich narratives, to metaphorical formulations and finally into concrete prototypes of the platform. In this paper, we propose a pluralist approach where each theoretical lens has merits depending on the context of the use as each lens holds unique characteristics [15]. Using those boundary objects actively is what we call co-designing with boundary objects, which we would like to suggest as a design approach when designing healthcare platforms with heterogenous users. As the design process advances, the boundary objects have a range of functionalities and characteristics that can be helpful for different purposes, depending on what the design process needs at that time. The previous boundary objects are not replaced but are however backgrounded and the new ones, needed for the phase at hand, are foregrounded instead. The boundary objects needed are at first open and at last, closed. Using narratives to form a collaborating practice, then moving towards metaphorical boundary objects to formulate goals before starting the structured and closed prototypes to initiate concrete practice discussions, can be beneficial when designing platforms for heterogeneous users, and especially beneficial in design processes within healthcare where complexity is high and the institutional and regulated environment calls for a more delicate design approach; such as the approach of codesigning with boundary objects. 


\section{Compliance with ethical standards}

Conflict of interest The authors declare that they have no conflict of interest.

Open Access This article is distributed under the terms of the Creative Commons Attribution 4.0 International License (http:// creativecommons.org/licenses/by/4.0/), which permits unrestricted use, distribution, and reproduction in any medium, provided you give appropriate credit to the original author(s) and the source, provide a link to the Creative Commons license, and indicate if changes were made.

\section{References}

1. Islind AS. Platformization: co-designing digital platforms in practice. 2018, University West.

2. Roland LK et al. P for platform. Architectures of large-scale participatory design. Scand J Inf Syst. 2017;29(2).

3. Islind AS et al. Co-creation and fine-tuning of boundary resources in small-scale platformization. in Scandinavian Conference on Information Systems. 2016. Springer.

4. Islind AS, et al. The virtual clinic: two-sided affordances in consultation practice. Comput Supported Coop Work, 2019.

5. Richardson WC, et al. Crossing the quality chasm: a new health system for the 21st century. Washington, DC: Institute of Medicine, National Academy Press; 2001.

6. Roa LM, Reina-Tosina J. Design implications of e-health systems for a sustainable growth. Heal Technol. 2016;6(1):7-9.

7. Gausepohl KA, et al. A conceptual model for the role of storytelling in design: leveraging narrative inquiry in user-centered design (UCD). Heal Technol. 2016;6(2):125-36.

8. Galway L, et al. Stakeholder involvement guidelines to improve the design process of assistive technology: lesson from the development of the MPVS system. Heal Technol. 2013;3(2):119-27.

9. Bartel CA, Garud R. Narrative knowledge in action: Adaptive abduction as a mechanism for knowledge creation and exchange in organizations. The Blackwell handbook of organizational learning and knowledge management, 2003: 324-342.

10. Bechky BA. Sharing meaning across occupational communities: the transformation of understanding on a production floor. Organ Sci. 2003;14(3):312-30.

11. Boland RJ, Tenkasi RV. Perspective making and perspective taking in communities of knowing. Organ Sci. 1995;6(4):350-72.

12. Carlile PR. A pragmatic view of knowledge and boundaries: boundary objects in new product development. Organ Sci. 2002;13(4):442-55.

13. Carlile PR. Transferring, translating, and transforming: an integrative framework for managing knowledge across boundaries. Organ Sci. 2004;15(5):555-68.

14. Levina N. Collaborating on multiparty information systems development projects: a collective reflection-in-action view. Inf Syst Res. 2005;16(2):109-30.

15. Nicolini D, Mengis J, Swan J. Understanding the role of objects in cross-disciplinary collaboration. Organ Sci. 2012;23(3):612-29.

16. Pawlowski SD, Robey D. Bridging user organizations: knowledge brokering and the work of information technology professionals. MIS Quart: Manag Inform Syst. 2004;28(4):645-72.

17. Star SL, Griesemer JR. Institutional ecology, 'translations' and boundary objects: amateurs and professionals in Berkeley's Museum of Vertebrate Zoology, 1907-39. Soc Stud Sci. 1989;19: $387-420$.
18. Star SL. The structure of ill-structured solutions: boundary objects and heterogeneous distributed problem solving. Distrib Artif Intell. 1990;2:37-54.

19. Star SL. This is not a boundary object: reflections on the origin of a concept. Sci Technol Hum Values. 2010;35(5):601-17.

20. Wenger E. Communities of practice and social learning systems. Organization. 2000;7(2):225-46.

21. Kimble C, Grenier C, Goglio-Primard K. Innovation and knowledge sharing across professional boundaries: political interplay between boundary objects and brokers. Int J Inf Manag. 2010;30(5): 437-44.

22. Bergman M, Lyytinen K, Mark G. Boundary objects in design: an ecological view of design artifacts. J Assoc Inf Syst. 2007;8(11): 546.

23. Kensing F, Greenbaum J. Heritage: having a say, in Routledge international handbook of participatory design. 2013, Routledge; 21-36.

24. Joshi SG, Bratteteig T. Designing for prolonged masteryOn involving old people in participatory design. Scand J Inf Syst. 2016;28(1): 3-36.

25. Sanders EB-N, Stappers PJJC-D. Co-creation and the new landscapes of design 2008. 4(1): p. 5-18.

26. Joshi SG. Designing for capabilities: a phenomenological approach to the Design of Enabling Technologies for older adults. 2017.

27. Sanders EB-N, Stappers PJ. Co-creation and the new landscapes of design. Co-design. 2008;4(1):5-18.

28. Islind AS. The "PantryApp": Design Experiences from a UserFocused Innovation Project about Mobile Services for Senior Citizens. In International Working Conference on Transfer and Diffusion of IT. 2014. Springer.

29. Willermark S. Digital Didaktisk Design: Att utveckla undervisning i och för en digitaliserad skola. 2018, Högskolan Väst.

30. Suchman. Do categories have politics? The language/action perspective reconsidered. Computer supported cooperative work. Int J. 1994;2(3):177-91.

31. Akkerman SF, Bakker A. Boundary crossing and boundary objects. Rev Educ Res. 2011;81(2):132-69.

32. Brown JS, Duguid P. Organizational learning and communities of practice: toward a unified view of working, learning, and innovation. Organ Sci. 1991;2(1):40-57.

33. Cook SDN, Brown JS. Bridging epistemologies: the generative dance between organizational knowledge and organizational knowing. Organ Sci. 1999;10(4):381-400.

34. Islind AS, Lundh Snis U. Learning in home care: a digital artifact as a designated boundary object-in-use. J Work Learn. 2017;29(7/8): 577-87.

35. Islind AS, Snis UL. From co-design to co-care: designing a collaborative practice in care. Syst Signs Act. 2018;11(1):1-24.

36. Pawlowski SD, Robey D. Bridging user organizations: knowledge brokering and the work of information technology professionals. MIS Q, 2004; 645-672.

37. Swan J, et al. The object of knowledge: the role of objects in biomedical innovation. Hum Relat. 2007;60(12):1809-37.

38. Koskinen KU. Metaphoric boundary objects as co-ordinating mechanisms in the knowledge sharing of innovation processes. Eur J Innov Manag. 2005;8(3):323-35.

39. Henderson K. Flexibile sketches and inflexible data bases: visual communication, conscription devices, and boundary objects in design engineering. Sci Technol Human Values. 1991;16:448-73.

40. Lutters WG, Ackerman MS. Achieving safety: a field study of boundary objects in aircraft technical support. In Proceedings of the 2002 ACM conference on Computer supported cooperative work. 2002. ACM.

41. Berg M, Bowker G. The multiple bodies of the medical record. Sociol Q. 1997;38(3):513-37. 
42. Dalsgaard, P., K. Halskov, and D.A. Basballe. Emergent boundary objects and boundary zones in collaborative design research projects. In Proceedings of the 2014 conference on Designing interactive systems. 2014. ACM.

43. Ewenstein B, Whyte J. Knowledge practices in design: the role of visual representations asEpistemic objects'. Organ Stud, 2009.

44. Nandhakumar J, Panourgias NS, Scarbrough H. From knowing it to "getting it": envisioning practices in computer games development. Inf Syst Res. 2013;24(4):933-55.

45. Dourish P. Implications for design. In Proceedings of the SIGCHI conference on Human Factors in computing systems. 2006. ACM.

46. Beyer H, Holtzblatt K. Contextual design. Interactions. 1999;6(1): 32-42.

47. Anderson RJ. Representations and requirements: the value of ethnography in system design. Human-Comput Interact. 1994;9(3): 151-82.

48. Baskerville RL, Myers MD. Design ethnography in information systems. Inf Syst J. 2015;25(1):23-46.

49. Matthews T, Judge T, Whittaker S. How do designers and user experience professionals actually perceive and use personas? Proceedings of the SIGCHI conference on human factors in computing systems. 2012. ACM.

50. Cooper A. The inmates are running the asylum: [Why high-tech products drive us crazy and how to restore the sanity]. IN, USA: Sams Indianapolis; 2004.

51. Boyatzis RE. Transforming qualitative information: thematic analysis and code development. 1998: Sage.
52. Islind AS et al. Shift in translations: Data work with patientgenerated health data in clinical practice. Health Informatics J. 2019. https://doi.org/10.1177/1460458219833097.

53. Cerna K, Islind AS, Lundin J, \& Steineck G. Decision-support system for cancer rehabilitation: designing for incorporating of quantified data into an existing practice. In Proceedings of the 10th Nordic Conference on Human-Computer Interaction (pp. 747-753). 2018. ACM.

54. Ellingsen G, Monteiro E. Electronic patient record development in Norway: the case for an evolutionary strategy. Health Policy Technol. 2012;1(1):16-21.

55. Fitzgerald G, Russo NL. The turnaround of the London ambulance service computer-aided despatch system (LASCAD). Eur J Inf Syst. 2005;14(3):244-57.

56. Monteiro E, et al. From artefacts to infrastructures. Comput Supp Coop Work (CSCW). 2013;22(4-6):575-607.

57. Norström L, Islind AS, Vallo Hult H. Balancing the Social Media Seesaw in Public Sector: A Sociomaterial Perspective. IRIS Selected Papers of the Information Systems Research Seminar in Scandinavia. 2017. Tapir Akademisk Forlag.

Publisher's note Springer Nature remains neutral with regard to jurisdictional claims in published maps and institutional affiliations. 